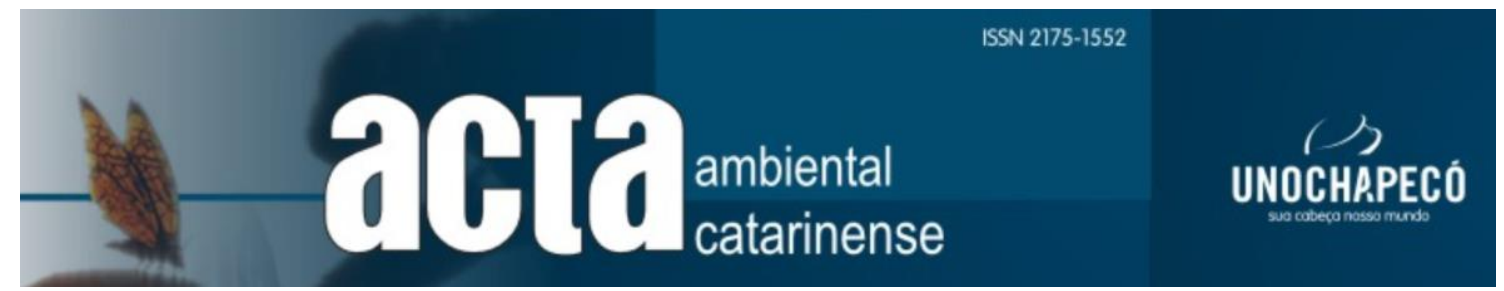

\title{
GERENCIAMENTO DE ÓLEO RESIDUAL - PROPOSTA DE INTERVENÇÃO PARA A CIDADE DE PALMAS - TO
}

\author{
Ana Karla Carvalho Aragão de Faria ${ }^{1 *}$; Juan Carlos Valdés Serra ${ }^{2}$ \\ ${ }^{1}$ Mestranda do Programa de Pós-Graduação em Engenharia Ambiental PPGEA - Universidade Federal do Tocantins (UFT), Quadra 109 \\ Norte, Avenida NS-15, ALCNO-14, Plano Diretor Norte | 77001-090 | Palmas/TO. \\ ${ }^{2}$ Professor do Programa de Pós-Graduação em Engenharia Ambiental PPGEA - Universidade Federal do Tocantins (UFT), Quadra 109 \\ Norte, Avenida NS-15, ALCNO-14, Plano Diretor Norte | 77001-090 | Palmas/TO.
}

*E-mail: anakarlaaragao@gmail.com

\section{Resumo}

Um dos resíduos que mais contamina os recursos hídricos e causa grandes impactos ao sistema de tratamento de esgoto é o óleo de fritura residual, embora não seja do conhecimento de muitas pessoas e por isso não recebe a atenção devida da forma de armazenamento e correta destinação final deste resíduo. Este estudo tem como objetivo analisar o gerenciamento do óleo de fritura residual em âmbito nacional e internacional para chegar em uma proposta de intervenção na cidade de Palmas-TO. A estratégia utilizada para alcançar este objetivo é a utilização de pesquisa exploratória e métodos diretos dedutivos e de interpretação para chegar a um modelo ideal para a capital. Esta análise propende substanciar uma tomada de decisão na formulação do melhor modelo de gerenciamento do óleo de fritura residual de acordo com a realidade local da cidade de Palmas-TO.

Palavras-chave: Óleo de Fritura Residual, Gerenciamento, Intervenção.

\begin{abstract}
One of the residues that most contaminates water resources and causes major impacts on the sewage treatment system is waste frying oil, although it is not known to many people and therefore does not receive due attention of the storage form and proper disposal. of this residue. This study aims to analyze the management of waste oil frying nationally and internationally to arrive at an intervention proposal in the city of Palmas-TO. The strategy used to achieve this goal is to use exploratory research and direct deductive and interpretative methods to arrive at an ideal model for the capital. This analysis proposes $t o$ substantiate a decision-making process in the formulation of the best residual frying oil management model according to the local reality of Palmas-TO.
\end{abstract}

Keywords: Residual Frying Oil, Management, Intervention.

\section{Introdução}

As principais atividades que acarretam a poluição dos recursos hídricos são esgoto doméstico, esgoto industrial, depósito inadequado de lixo, atividades de mineração e agricultura, indústrias e navegação (SANTOS, 2012). A presença do óleo vegetal nos rios cria uma película superficial que diminui a entrada de luz e a oxigenação da água, comprometendo assim, a base da cadeia alimentar aquática. Com o desequilíbrio da quantidade de nutrientes, ocorre a proliferação excessiva de algas e consequente eutrofização do ambiente (BORTOLUZZI, 2011). 
Além dos problemas relacionados ao descarte de resíduos sólidos, destaca-se a destinação final de produtos que são utilizados diariamente pela população, e que nem sempre recebe o tratamento ou aproveitamento necessário para uma conservação e preservação ambiental, como o óleo de cozinha. O Óleo de Fritura Residual (OFR) possui grande potencial de se tornar matéria prima para fabricação de produtos como tinta, sabão, massa de vidraceiro, energia elétrica, formulação de tinta de impressão e, dentre outros, no biodiesel (SUAREZ e MELLO, 2011).

De acordo com a Companhia de Saneamento Básico do Estado de São Paulo - Sabesp, (2016), cada litro de óleo pode contaminar até 12 mil litros de água, no entanto, além de mensurar ou valorar o dano que esse resíduo pode gerar, devese entender o grau de poluição deste e que o mesmo, por meio da reciclagem, traz um ganho ambiental e social para a sociedade. A reciclagem proporciona a redução dos gastos com o tratamento de água e elimina um passivo ambiental resultante da emissão de produtos químicos necessários para o tratamento. Os óleos e graxas são hidrocarbonetos como sabão, gorduras e óleos, quando em excesso podem interferir nos processos biológicos aeróbicos e anaeróbicos, ocasionando a eutrofização da água, causada pela barreira que estes criam, dificultando a entrada de luz e oxigenação da água, comprometendo assim a base da cadeia alimentar aquática. Alémdisso, interfere no tratamento de águas residuais, sendo impossível de ser usada pela população e animais (BORTOLUZZI, 2011).

A Política Nacional de Resíduos Sólidos instituída pela Lei 12.305/2010, em seu Art. 18, preconiza que a elaboração de um Plano Municipal de Gestão Integrada de Resíduos Sólidos é condição para que os municípios tenham acesso a recursos da União, ou por ela controlados, destinados a empreendimentos e serviços relacionados à limpeza urbana $\mathrm{e}$ ao manejo de resíduos sólidos, ou para serem beneficiados por incentivos ou financiamentos de entidades federais de crédito ou fomento para tal finalidade (BRASIL, 2010).

Assim, é indispensável o gerenciamento e projetos de intervenção que visam a coleta e a reciclagem deste resíduo proporcionando a saúde ambiental e social de toda uma comunidade. Logo, este trabalho busca fazer uma análise em âmbito nacional e internacional de projetos voltados ao gerenciamento do óleo de cozinha afim de reconhecer e/ou desenvolver o mais apropriado para a realidade da cidade de Palmas.

\section{Material e Métodos}

O trabalho que ora se inicia utilizar-se-á o método dedutivo, partindo de informações/proposições gerais para o caso particular, ou seja, será necessária a análise de amplas informações sobre o gerenciamento do óleo de fritura residual nos diversos países e cidades brasileiras.

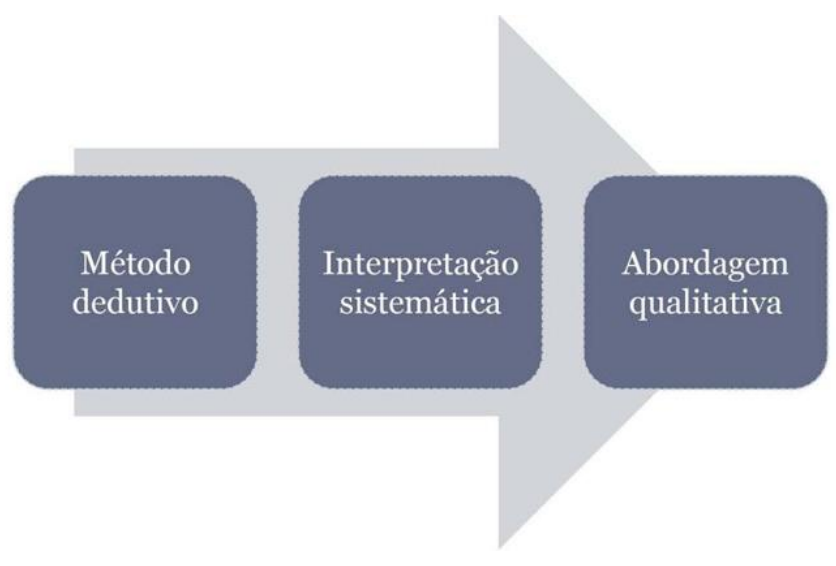

O método dedutivo consiste em perceber problemáticas, falhas, dúvidas ou discrepâncias em teorias e conhecimentos já existentes, onde são formuladas hipóteses ou soluções para tais problemas. Uma vez feita a análise dos resultados, as soluções ou hipóteses podem ser rejeitadas ou confirmadas (DINIZ, 2015).

Faz-se necessária a aplicação da técnica de interpretação sistemática, bem como a interatividade de vários ramos das ciências ambientais e sociais. Por fim, há de se dizer que a abordagem qualitativa será utilizada, pois buscar-se-á analisar a situação do descarte do óleo de fritura no tocante à preservação e conservação do meio ambiente, no intuito de demonstrar a importância do gerenciamento, não somente para o meio, mas para todos aqueles que, de certa forma, estão correlacionados às questões ambientais. $\mathrm{Na}$ abordagem qualitativa, o pesquisador troca as vinculações estatísticas pelas exposições e as conexões causais objetivas pelas explicações (MARTINS et al,1989).

\section{Resultados}

Para Kraemar (2014), constituímos a sociedade dos resíduos e só despertamos recentemente para esta realidade; um dado relevante para essa afirmativa é de que nos últimos 20 anos a população mundial cresceu menos que o volume de resíduos produzido por ela. De 1970 a 1990 a população do planeta aumentou em $18 \%$, enquanto a quantidade de resíduos passou a ser $25 \%$. No período de 1980 a 2005, a quantidade de Resíduos Sólidos Urbanos (RSU) per capita aumentou 29\% na América do Norte, $35 \%$ na Organização de Cooperação e de Desenvolvimento Económico (OCDE), e 54\% na UE15, acompanhando, de uma forma geral, o produto interno bruto (PIB) dos países (SJÖSTÖM e ÖSTBLOM, 2010). No Brasil, publicações recentes deixam claro o problema: a geração anual evoluiu $0,8 \%$ entre 2015 e 2016 e chegou a 214.405 t/dia de RSU gerados no país. Apesar dos dados mostrarem uma redução de cerca de $2 \%$ em relação ao ano de 2015 , o volume total mantém-se acima das 200.000 toneladas por dia, o que implica em pouco mais de um quilograma de resíduos descartados por pessoa diariamente (ABRELPE, 2016).

O Óleo de Fritura Residual (OFR) é produto do consumo de óleos vegetais comestíveis virgens refinados e constitui como um resíduo sólido urbano e industrial que possui 
produção diária em domicílios, bares, restaurantes e demais estabelecimentos comerciais e industriais.

O consumo per capita deste produto no Brasil é de 20 litros/ano, porém a quantidade do seu resíduo gerado coletado é de menos 1\% (ECOLEO, 2018). Para iniciar discussões com relação a gestão deste resíduo é necessária a vontade dos gestores em criar políticas públicas voltadas às questões ambientais relacionadas à reciclagem do óleo residual para só então criar-se um plano de gerenciamento adequado. A análise realizada em âmbito internacional pode ser observado na Tabela 1 com as principais informações acerca dos projetos desenvolvidos nos países estudados. Conforme observado na Tabela 2, os parágrafos a seguir detalha cada caso em questão no que tange às iniciativas voltadas ao gerenciamento do óleo de fritura residual.

Tabela 1. Modelos de gerenciamento do óleo de fritura residual em âmbito internacional.

\begin{tabular}{|c|c|c|}
\hline EUROPA & AUSTRÁLIA & EUA \\
\hline $\begin{array}{l}>\text { Alguns países da UE } \\
\text { (Portugal, Espanha, Itália, } \\
\text { Grécia e Bélgica) se } \\
\text { uniram em um projeto } \\
\text { denominado RecOil; } \\
>\text { Principais formas de } \\
\text { coleta do resíduo acontece } \\
\text { por meio de pontos de } \\
\text { entrega voluntária em } \\
\text { locais de fácil acesso e } \\
\text { com estrutura própria e } \\
\text { adaptada (presença de } \\
\text { funil) para o cidadão } \\
\text { dispor da maneira mais } \\
\text { simples possivel. }\end{array}$ & 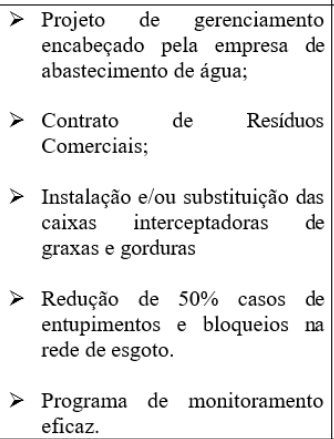 & $\begin{array}{l}>\text { Califórnia } \\
>\text { Portaria de } \\
\text { gordura, óleos } \\
\text { e graxa para } \\
\text { instalação de } \\
\text { interceptores; } \\
>\text { Programa de } \\
\text { monitorament } \\
\text { o eficaz. }\end{array}$ \\
\hline $\begin{array}{l}\text { Utilização do resíduo para } \\
\text { fabricação de biodisel. }\end{array}$ & & \\
\hline
\end{tabular}

Tabela 2. Modelos de gerenciamento do óleo de fritura residual no Brasil.

\begin{tabular}{|c|c|}
\hline Rio de Janeiro & $\begin{array}{l}\text { PROVE - Programa de Reaproveitamento de } \\
\text { Óleos Vegetais, criado em } 2008 \text { para } \\
\text { incentivar a criação de cooperativas de coleta } \\
\text { seletiva de resíduos sólidos e liquidos (no } \\
\text { caso, o óleo de cozinha) e, a geração de } \\
\text { trabalho e renda para os catadores } \\
\text { organizados (RIO DE JANEIRO, 2017). O } \\
\text { programa atende } 92 \text { municípios por meio } \\
\text { das cooperativas e possui mais de } 50 \\
\text { cooperativas cadastradas, para as quais é } \\
\text { oferecido o transporte para coleta do óleo. O } \\
\text { óleo coletado é prioritariamente } \\
\text { orientado para a fabricação do biodiesel, } \\
\text { mas pode ser também comercializado para a } \\
\text { indústria de sabão. Não há relação contratual } \\
\text { com as cooperativas nem relacionamento e } \\
\text { incentivos às empresas recicladoras e } \\
\text { transformadoras do OFR (SILVA, 2018). O } \\
\text { descarte pode ser feito diretamente nas } \\
\text { cooperativas ou parceiras do programa e em } \\
\text { alguns pontos de entrega voluntária } \\
\text { espalhados pela cidade como unidades de } \\
\text { ensino e outras. Além disso o programa conta } \\
\text { com um serviço de disque coleta, onde o } \\
\text { munícipe que quiser descartar pode ligar para } \\
\text { receber orientações quanto aospontos } \\
\text { disponiveis para descarte. }\end{array}$ \\
\hline São Paulo & $\begin{array}{l}\text { PROL - Projeto de fomento à reciclagem do } \\
\text { óleo de cozinha usado desenvolvido pela } \\
\text { Sabesp (Companhia de Saneamento básico de } \\
\text { São Paulo). O projeto conta com parcerias } \\
\text { com ONG's, empresas, Associações e } \\
\text { Cooperativas de catadores. Funciona por } \\
\text { meio de pontos de entrega voluntária } \\
\text { (supermercados e redes parceiras como o Pão } \\
\text { de Açúcar), condominios, dentre outros. O } \\
\text { munícipe recebe um funil para facilitar o } \\
\text { depósito do resíduo na garrafa pet e quando } \\
\text { esta alcança sua capacidade máxima, pode } \\
\text { ser entregue em algum dos ecopontos. A } \\
\text { destinação é para as Associações e } \\
\text { Cooperativas de catadores interessadas e } \\
\text { parceiras, fabricantes de biodiesel, sabão, } \\
\text { tintas a óleo, massa de vidraceiro,entre } \\
\text { outros usos (SABESP, 2016). }\end{array}$ \\
\hline
\end{tabular}




\begin{tabular}{|c|c|}
\hline Minas Gerais & $\begin{array}{l}\text { RECÓLEO (Belo Horizonte) - Funciona com } \\
\text { distribuição de vasilhames para os cidadãos } \\
\text { armazenarem o óleo realizando o cadastrode } \\
\text { cada um, onde por meio de um rotapr é } \\
\text { estabelecida é feita a visita periódica para } \\
\text { recolhimento de vasilhames cheios e troca } \\
\text { por novo vasilhame vazio. Dependendo do } \\
\text { volume coletado, o munícipe se benefícia em } \\
\text { permuta por produtos de limpeza. O resíduo } \\
\text { então passa pelo beneficiamento em } \\
\text { empresas recicladoras que destina o resíduo } \\
\text { sólido oriundo do tratamento para } \\
\text { compostagem e o óleo tratado para } \\
\text { empresas fabricantes de biodiesel } \\
\text { (MEDEIROS, 2018). }\end{array}$ \\
\hline Porto Alegre & $\begin{array}{l}\text { O programa está dentro do programa } \\
\text { geral de coleta seletiva do município } \\
\text { enquadrado como resíduo perigoso. O } \\
\text { descarte é feito por meio de ecopontos com a } \\
\text { utilização de garrafas pet ou de vidro pelos } \\
\text { munícipes e o resíduo é destinado para } \\
\text { produção de ração animal e biodiesel } \\
\text { (PLAUTZ, 2019). }\end{array}$ \\
\hline Curitiba & $\begin{array}{l}\text { - Câmbio Verde (CV) e o Lixo Tóxico } \\
\text { Domiciliar (LTD) - Programas públicos de } \\
\text { coleta e reciclagem do OFR, onde o primeira } \\
\text { trata-se da troca de residuos recicláveis, } \\
\text { incluindo o óleo por frutas e verduras, e o } \\
\text { segundo da coleta de resíduos perigosos. Os } \\
\text { materiais são encaminhados para as } \\
\text { cooperativas de catadores que vendem para } \\
\text { empresas ambientalmente certificadas para } \\
\text { darem continuidade ao processo de } \\
\text { reciclagem. Nestes programas a coleta é } \\
\text { itinerante e esporádica (LARSENet al, 2019). } \\
\text { - Programa Ecosolidariedade com } \\
\text { utilização de pontos de entrega voluntária em } \\
\text { supermercados, unidades de ensino e demais } \\
\text { parceiros. } \\
\text { - Cidadãos comuns e de forma informal } \\
\text { fazendo coleta porta-a-porta em "carros do } \\
\text { óleo". } \\
\text { - Indústrias químicas utilizam o resíduo } \\
\text { para produção de lubrificantes, materiais de } \\
\text { limpeza e afins. }\end{array}$ \\
\hline
\end{tabular}

I. Europa
Na União Européia estima-se que a geração de OFR no setor doméstico é de 1.748 milhões de toneladas por ano, onde se computa que um percentual de mais de $60 \%$ sejam descartados incorretamente (European Biomass Industry Association, 2015).

Alguns países da UE (Portugal, Espanha, Itália, Grécia e Bélgica) se uniram em um projeto denominado RecOil com o objetivo de reunir informações e dados quanto aos programas existentes em suas cidades de gerenciamento do óleo usado como a forma de coleta e transporte, além de campanhas promocionais destes.

$\mathrm{O}$ projeto concluiu que as principais formas de coleta do resíduo acontece por meio de pontos de entrega voluntária em locais de fácil acesso e com estrutura própria e adaptada (presença de funil) para o cidadão dispor da maneira mais simples possível. Além disso, observou-se que o destinação mais utilizada é utilização do resíduo para fabricação de biodisel, sendo que este, na maioria dos casos é vendido no mercado e parte devolvido para as fontes promotoras para ser utilizado no abastecimento da frota de transporte público (Wallace, T., et al., 2017).

\section{Austrália}

$\mathrm{Na}$ Austrália, duas das empresas responsáveis pelo abastecimento de água e esgoto de Melborne, City West Water (CWW) e South East Water (SEW), desenvolveram um projeto que iniciou em 1995 a fim de solucionar a problemática das gorduras e graxas presentes no esgoto (Alam, A., 2003).

Identificaram que as maiores fontes destes resíduos eram os centros comercias como restaurantes, bares e etc, começaram então a focar a resolução da problemática nestas instalações. O projeto foi dividido em três fases, a primeira constituiu em garantir que todos os comércios que despejam água residual que não seja doméstica, possuíam o Contrato de Resíduos Comerciais, onde obriga o estabelecimento instalar o coletor de graxa que consiste num dispositivo de tratamento que separa óleos, gorduras e sólidos e os impede de entrar no esgoto (Scoble e Day, 2002).

Os autores ainda descrevem que as fases dois e três constituíram em garantir que todas as instalações comerciais que descarregavam resíduos gordurosos tivessem o coletor de graxa ou interceptor de graxa em um tamanho adequado, e se certificar de que todos os interceptores comerciais de graxa, ou equivalentes, fossem limpos regularmente ou mantido em bom funcionamento, respectivamente.

Isso foi possível por meio de um programa de monitoramento denominado Wastelog, que gerava dados e informações quanto a situação das saídas das bombas dos interceptores de graxa comerciais.

Essa forma de gerenciamento dos resíduos gordurosos gerou um resultado satisfatório para as cidades, onde observou uma redução de $50 \%$ dos casos de entupimentos e bloqueios na rede de esgoto causados por gorduras e graxas, como o óleo de fritura residual.

\section{EUA}


$\mathrm{Na}$ comunidade da cidade de Mendocino Serviços Distritais (MCCSD - Mendocino City Community Services District), no estado da Califórnia nos EUA, verificou-se diversos casos de backups e bloqueios de esgoto resultantes do acúmulo de graxas. Em todo o país, a principal causa de transbordamento de esgoto sanitário é de gorduras, óleos e graxas (FOG). Em um esforço para resolver esse problema, o Conselho Regional de Controle da Qualidade da Água da Califórnia determinou que a cidade criasse um Programa para os geradores de gorduras, óleos e graxas, onde as instalações não residenciais são monitoradas para descargas de graxa (Greer, 2010).

Em dezembro de 2009, a cidade de MCCSD adotou uma Portaria de Gordura, Óleos e Gordura, que exigia dispositivos de remoção de graxa em instalações de serviço de alimentação, bem como interceptor de graxa / armadilha de limpeza e relatórios. Além disso, um programa de inspeção foi implementado para visitar cada instalação e verificar o cumprimento da portaria local.

No Brasil ainda são poucas as iniciativas de gerenciamento do óleo de fritura residual - Rio de Janeiro, São Paulo, Minas Gerais, Curitiba, Porto Alegre e outras, no entanto pode-se observar que essas iniciativas partem algumas vezes por entidades privadas e não do poder público, além disso, observa-se que a maior parte delas é de cidades mais desenvolvidas e populosas.

A Tabela 2 mostra de forma sucinta os modelos adotados por algumas das principais cidades no Brasil.

Como observado na Tabela 2, a maioria das iniciativas prevêem a utilização de pontos de entrega voluntária como forma de facilitar o engajamento pelos cidadãos e a destinação mais comum do resíduo é a fabricação de biodiesel ou nos programas mais informais, para fabricação de sabão.

\section{Discussão}

O município de Palmas conta com uma iniciativa voltada ao gerenciamento do Óleo de Fritura Residual, trata-se do programa Renova Palmas, que surgiu como um projeto de recolhimento e incentivo à entrega de óleo de cozinha usado, bem como o fomento à sensibilização e educação ambiental referente ao descarte destes resíduos, indicando e esclarecendo à população dos malefícios e impactos negativos que isso acarreta ao meio e ao dia-a-dia do cidadão.

Como o projeto ainda está em fase de implementação e possui gargalos a serem superados e caminhos de melhoria contínua em busca do sucesso, a necessidade de se adequar a realidade e condições locais de gestão ambiental, torna-se um importante aliado ao poder público e tomadores de decisão ao implantar um projeto com tamanha importância e significância.

Com relação ao armazenamento temporário feito pelos próprios munícipes, sugere-se a utilização da garrafa pet e a disponibilização da poder público de um funil apropriado para facilitar o manuseio do resíduo e assim realizar o armazenamento correto sem qualquer perigo de vazamento.
Neste sentido, o programa já existente no município, Renova Palmas, poderá seguir com a ideia inicial de disponibilizar um recipiente, ora denominado de biocoletor, que acopla a garrafa pet e conta com um fechamento em forma de funil, respondendo as expectativas e resultados esperados supracitados. O recipiente pode ser observado na Figura 1.

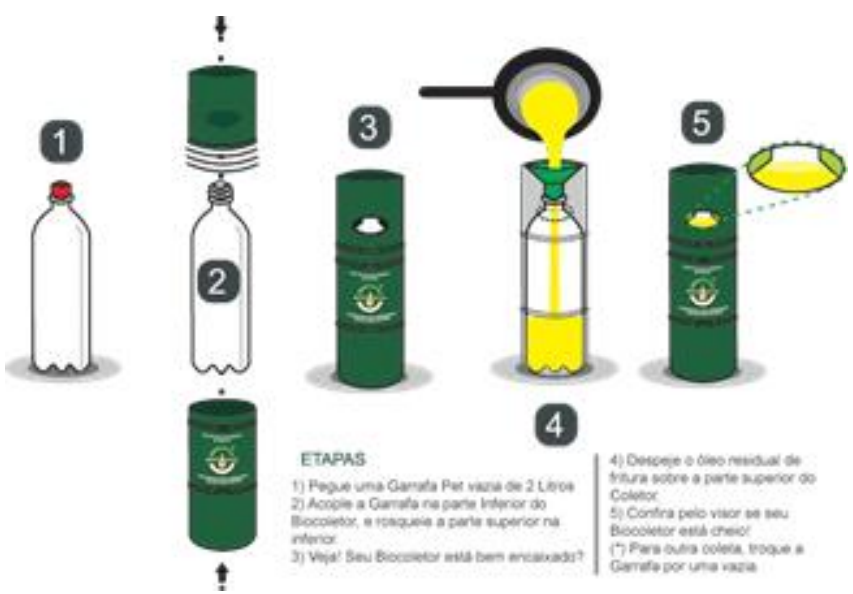

Figura 1. Biocoletor para armazenamento do óleo de fritura residual (Fonte: FMA, 2018).

Os biocoletores são fabricados a partir de material reciclado para acondicionamento da garrafa pet de $2 \mathrm{~L}$ e possibilita ao cidadão após despejar o resíduo em algum ponto de entrega voluntária, reutilizar a mesma garrafa para armazenamento temporário.

No que diz respeito à forma de acondicionamento do óleo e a forma de coleta primária diretamente dos munícipes, após a pesquisa exploratória, entende-se que a forma mais viável e utilizada nas cidades nacionais e internacionais ainda é a disponibilização de pontos de entrega voluntária espalhados pela cidade, de forma democrática e estrategicamente pensada a fim de alcançar o maior número depessoas.

Ressalta-se que após algumas experiências vivenciadas em projetos municipais e campanhas de sensibilização ambiental na capital palmense, observou-se um interesse forte por parte dos moradores em ter um local onde possa descartar de forma ambientalmente correta o óleo de cozinha, necessitando apenas da disponibilização desses locais devidamente identificados e próprios.

Insta citar que a capital é conhecida por uma ser uma "cidade saudável" apresentando um dos menores índices de obesidade (Ministério da Saúde, 2019) onde grande parte dos moradores praticam atividade física regularmente e tem buscado se alimentar cada vez mais de forma saudável, eliminando assim, de forma crescente, as frituras e preparações de comidas que utilizam o óleo em grandes quantidades e de forma regular. Sendo assim, o consumo doméstico do óleo e a consequente geração do resíduo, tende a diminuir cada vez mais, dispensando assim alguma forma de separação de óleo domiciliar mais avançada tecnologicamente, tornando o armazenamento em garrafa pet e a disponibilização de pontos de entrega voluntária suficiente e satisfatória. 
Como forma de compensação e incentivo aos munícipes que fizerem esse armazenamento correto e entrega voluntária, poderá ser utilizado a metodologia adotada em Curitiba, realizando a "troca sustentável" onde o cidadão receberá na troca do óleo residual, materiais de limpeza pré estabelecidos e divulgados e variado de acordo com a quantidade de óleo entregue. Ainda, o programa Renova Palmas também já conjectura a utilização dos pontos de entrega voluntária, sendo assim, segue nas Figura 2 e 3, o modelo previsto pelo programa que satisfaz as necessidades para um bom gerenciamento do óleo de cozinha, utilizando uma bombona de 200 litros em cada estrutura.

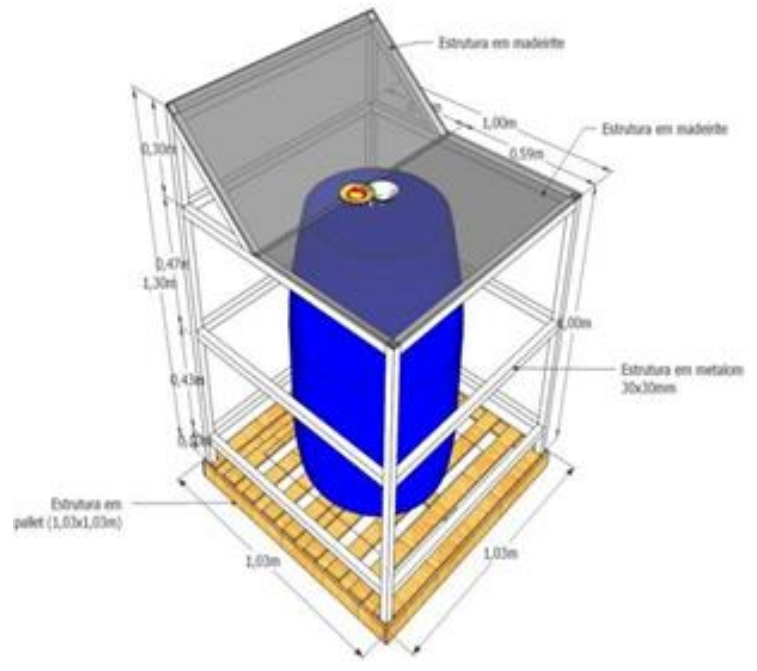

Figura 2. Layout interno do ponto de entrega voluntária (Fonte: FMA, 2018).

Destaca-se que entre os pontos estratégicos pensados para instalação dos pontos encontram- se as unidades de ensino, supermercados, órgãos públicos, feiras cobertas, hotéis e as próprias cooperativas e associações de catadores.

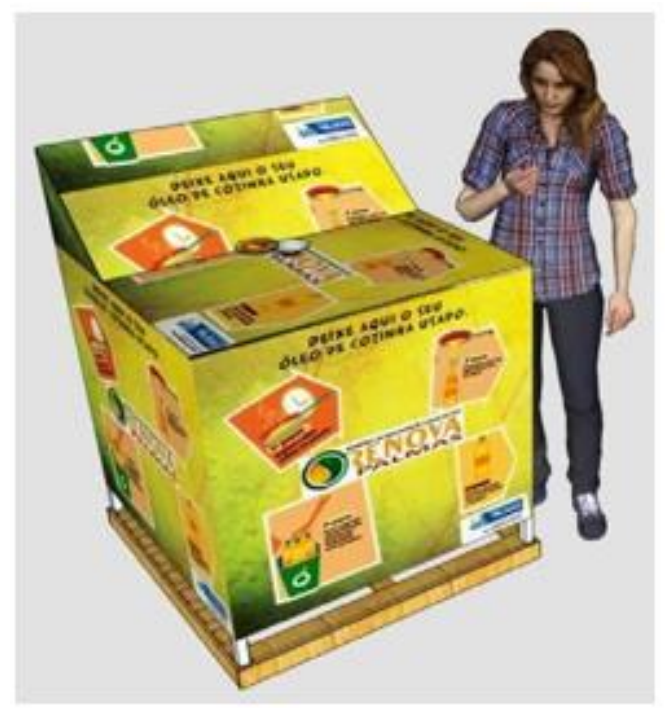

Figura 3. Layout externo do ponto de entrega voluntária (Fonte: FMA, 2018).
Analisando a situação dos grandes geradores, entende-se que os mesmos necessitam de uma atenção especial no que tange à separação e armazenamento do resíduo oleoso visto a sua capacidade de geração e necessidade de descarte constante. Desta forma, infere-se que a utilização e instalação de interceptadores de graxa e gorduras no tamanho ideal para o estabelecimento, bem como a formalização disso por meio de Portaria ou algum tipo de Contrato de Resíduos Comerciais, garantiria que todos os estabelecimentos comerciais da área alimentícia e/ou que gera e utiliza material oleoso como o óleo de cozinha em suas atividades principais, não despejassem o resíduo na rede de esgoto comum. Para tanto, sugere-se que tal garantia por meio de documento assinado seja realizada no processo de requerimento para funcionamento por parte da Vigilância Sanitária, atestando a necessidade de implantação do interceptador de graxas e gorduras, seja na fase de instalação do empreendimento ou mesmo na fase de renovação do seu documento junto à Vigilância.

Salienta-se que este documento poderá estar atrelado à Norma Regulatória NR9 que estabelece a obrigatoriedade da elaboração e implementação, por parte de todos os empregadores e instituições que admitam trabalhadores como empregados, o Programa de Prevenção de Riscos Ambientais (PPRA) (SAAD, 2005). Adicionalmente, como forma de compensação e incentivo aos grandes geradores, propõe-se um desconto em sua conta de água mensal oferecido pela própria Concessionária de saneamento da cidade, ora gerida pela BRK Ambiental. Para tanto, as caixas interceptadoras precisarão ser monitoradas constantemente afim de garantir o bom funcionamento das mesmas e assim, assegurar o desconto na fatura mensal doestabelecimento.

Por fim, no que diz respeito à destinação final, como Palmas se encontra geograficamente próxima á uma usina de beneficiamento e transformação do óleo de fritura residual em biodiesel, a Granol, localizada no município de Porto Nacional, sugere-se que o resíduo seja destinado a tal empresa nos moldes em que as cidades da Europa vem desenvolvendo, onde parte do biodiesel produzido pode voltar para o poder público para abastecer a frota de veículos municipais, conforme também já vem sendo acordado entre o órgão ambiental e a empresa fabricante.

\section{Conclusão}

Palmas é uma cidade rica em recursos hídricos, no entanto necessita de ações de preservação e conservação de seus mananciais a fim de se garantir um ambiente ecologicamente equilibrado para as presentes e futuras gerações. Deste modo, um correto gerenciamento do óleo de fritura residual contribuirá para a diminuição dos impactos negativos sobre os mesmos de forma a proporcionar uma saúde ambiental e sanitária para o ambiente e comunidade local, gerando resultados também em um contexto global.

Conforme observado na Tabela 3 acerca das principais semelhanças entre os países no gerenciamento do OFR, observa-se que o Brasil precisa avançar nos investimentos no 
que tange ao monitoramento de seus projetos e programas afim de se obter melhores e maiores resultados em suas metas. Além disso, o país necessita voltar as suas atenções aos grandes geradores do resíduo, que de fato são as maiores fontes poluidoras e portanto, requer maior esforço em dirimir tamanho impacto negativo ao meio.

Tabela 3. Principais semelhanças entre os países estudados.

\begin{tabular}{c|c|c|c|c}
\hline & EUA & AUSTRÁLIA & EUROPA & BRASIL \\
\hline $\begin{array}{c}\text { Utilização de } \\
\text { pontos de entrega } \\
\text { voluntária }\end{array}$ & & & $\mathrm{X}$ & $\mathrm{X}$ \\
\hline $\begin{array}{c}\text { Instalação de } \\
\text { caixas } \\
\begin{array}{c}\text { interceptadoras de } \\
\text { gorduras }\end{array}\end{array}$ & $\mathrm{X}$ & $\mathrm{X}$ & $\mathrm{X}$ & \\
\hline $\begin{array}{c}\text { Parceria com } \\
\text { cooperativas }\end{array}$ & & & & $\mathrm{X}$ \\
\hline $\begin{array}{c}\text { Utilização do óleo } \\
\text { na fabricação de } \\
\text { biodiesel }\end{array}$ & & $\mathrm{X}$ & $\mathrm{X}$ & $\mathrm{X}$ \\
\hline $\begin{array}{c}\text { Monitoramento } \\
\text { frequente e eficaz }\end{array}$ & $\mathrm{X}$ & & & \\
\hline
\end{tabular}

A preocupação com a preservação e conservação do meio ambiente tem apresentado números crescentes de qualidade $\mathrm{e}$ bem-estar social, sendo, portanto, um objetivo mundial a ser implantado e difundido entre uma sociedade consciente e operante nessas ações. Um programa que busca um processo de melhoria contínua requer os esforços de governantes preocupados e dispostos e de uma sociedade participativa que contribua efetivamente para o sucesso e o alcance de seus objetivos.

\section{Agradecimentos}

Agradeço à Universidade Federal do Tocantins por me proporcionar o acesso ao ensino e pesquisa de qualidade por meio do Programa de Pós Graduação em Engenharia Ambiental. Gratidão ao meu local de trabalho, Fundação Municipal de Meio Ambiente de Palmas por me proporcionar o engajamento nos programas e projetos que visam aumentar a sustentabilidade local e de forma consequente alcançando o nível global. É uma grande satisfação trabalhar neste meio e por essa causa de tamanha importância.

\section{Referências}

ALAM, A., 2003.Control and Management of Greasy Waste in Melbourne: Performance Review and Optimization Options. unpublished thesis (Masters Research). The University of Melbourne. Disponível em: <http://hdl.handle.net/11343/37434> Acessado em: 21 nov2019.

ABRELPE (2016).Panorama dos resíduos sólidos no Brasil.

Disponível em: $<$ http://www.abrelpe.org.br/Panorama/panorama2016.pdf >. Acesso em: 13 nov. 2019.
BRASIL.Política Nacional de Resíduos Sólidos. Lei 12305/2010. Brasília-Df. 2010.

BORTOLUZZI, Odete Roseli dos Santos.A poluição dos subsolos e águas pelos resíduos de óleo de cozinha. 2011.

DINIZ, Marco Túlio Mendonça.Contribuições ao ensino do método hipotético dedutivo a estudantes de Geografia. Geografia Ensino \& Pesquisa, v. 19, n. 2, p. 107- 111, 2015. ECÓLEO (Associação Brasileira Para Sensibilização, Coleta, Reaproveitamento e Reciclagem De Resíduos De Óleo Comestível). Reciclagem do óleo. Disponível em:

<http://ecoleo.org.br/projetos/6766-2/.\&gt>; Acesso em: 22 nov. 2019.

EUROPEAN BIOMASS INDUSTRY ASSOCIATION, 2015.Transformation of Used Cooking Oil into Biodiesel: from Waste to Resource - Position Paper, [online], Promotion of Used Cooking Oil Recycling for Sustainable Biodiesel Production (RecOil).Disponível em: <http://www.eubren.com/UCO to Biodiesel_2030_01.pdf > Accessado em 20 jul2019).

GREER, Diane et al. Reciclagem de óleo e graxa de resíduos locais em biodiesel.BioCycle, v. 51, n. 7, p. 56-59,2010.

KRAEMAR, M. E. P. A questão ambiental e os resíduos sólidos. Disponível em: <http://www.amda.org.br/imgs/up/Artigo_25.pdf.>. Acesso em 30 out. 2019.

LARSEN, Isabel; WEINSCHUTZ, Regina; KOLICHESKI, Mônica Beatriz.Logística Reversa Dos Óleos Residuais Em Curitiba Estudo De Caso Em Santa Felicidade E Projeto De Educação À Reciclagem. Revista Gestão \& Sustentabilidade Ambiental, v. 8, n. 1, p. 973-993, 2019.

MARTINS, J.; BICUDO, M. A. V.A pesquisa qualitativa em Psicologia: fundamentos e recursos básicos. São Paulo. EDUC / Moraes, 1989.

MEDEIROS, Beatriz Torres et al. A aplicabilidade da logística reversa na reciclagem do óleo vegetal usado.Revista Fatec Sebrae em debate-gestão, tecnologias e negócios, v. 5, n. 08, p. 52-52,2018.

MINISTÉRIO DA SAÚDE. Vigilância de Fatores de Risco e Proteção para Doenças Crônicas por Inquérito Telefônico.Brasília: Ministério da Saúde: Secretaria de Vigilância em Saúde, 2019. Disponível em: $\leq$ http://portalarquivos2.saude.gov.br/images/pdf/2019/jul ho/25/vigitel-brasil-2018.pdf >. Acesso em: 28 nov. 2019. 
PLAUTZ, Charlene Silva Freitas; DA SILVA, Jocileia Nascimento; PLAUTZ, Helierson Moura. Práticas Ambientais: Um estudo da coleta seletiva do lixo de Porto Alegre.Revista de Administração e Negócios da Amazônia, v. 10, n. 3, p. 90-106, 2019.

SAAD, Irene; GIAMPAOLI, Eduardo. Programa de prevenção de riscos ambientais-PPRA NR- 9 COMENTADA.São Paulo: ABHO, 2005.

SABESP (SP). Reciclagem de óleo.PROL - Programa de Reciclagem do óleo de cozinha. 2016. Disponível em:

<http://site.sabesp.com.br/uploads/file/asabesp_doctos/pro grama_reciclagem_oleo_completo.pdf $>$. Acesso em: 27 nov. 2019.

SANTOS, D. V.Disponibilidade e Potencial de Recolhimento de Óleo de Cozinha Usado Domiciliar no Distrito Federal: Uma Avaliação da Situação Atual e Perspectivas para um Aproveitamento Socioambiental e Sustentável. 2012. Dissertação (Mestrado em Planejamento e Gestão Ambiental). Universidade Católica de Brasília. Brasília, 2012.

SCOBLE, C., Day, N., 2002.Grease under control at south east water.In: 65th Annual Water Industry Engineers and Operators' Conference. Kardinia Heights Centre, Geelong, pp. 47e53, 4 and 5 September 2002.

SILVA, E. R.; MATTOS, U. A. O.; SANTOS, L. B.Análise da cadeia produtiva da reciclagem do óleo vegetal residual (cidade de Duque de Caxias, Rio de Janeiro, Brasil). O Social em Questão (Online), Ano XXI, n. 40, p. 267-288,2018. SJÖSTRÖM, M.; ÖSTBLOM, G. Decoupling waste generation from economic growth - A CGE analysis of the Swedish case.Ecological Economics, v. 69, Issue 7. 15 May 2010, p.1545- 1552 .

SUAREZ, P. A. Z. \& Mello, V. M. (2011).Gestão sustentável de óleos e gorduras residuais naUniversidade de Brasília: rumo à responsabilidade ambiental e social. In: Catalão, V . M.L. etal.(Orgs.).Universidade para o século XXI:educação e gestão ambientalna Universidade deBrasília(pp. 59-69). Brasília: Cidade Gráfica e Editora.

WALLACE, Thomas et al. International evolution of fat, oil and grease (FOG) waste management-A review.Journal of environmental management, v. 187, p. 424-435, 2017.

Recebido: $23 / 12 / 2019$

Aceito: $24 / 03 / 2020$ 